\title{
ДОХОДНОСТЬ СЕЛЬСКОГО ХОЗЯЙСТВА И ЭКОНОМИЧЕСКИЙ РОСТ В СИСТЕМЕ НАЦИОНАЛЬНЫХ СЧЕТОВ
}

\author{
D.S. Komshanov, I.G. Tolmachyova, \\ G.V. Antonov
}

\section{THE PROFITABILITY OF AGRICULTURE AND ECONOMIC GROWTH IN THE SYSTEM OF NATIONAL ACCOUNTS}

Рассмотрена важность системы национальных счетов как основного источника информации о состоянии экономики в целом и отдельных отраслей и формирования на основе этих данных экономической политики государства. Раскрыты недостатки измерения доходов и доходности сельского хозяйства в системе национальнъх счетов на уровне государства и в системе региональных счетов на уровне отдельных регионов, что связано с плохой наблюдаемостью сектора «домашние хозяйства» при их значительном удельном весе по отрасли «сельское хозяйство». Большая часть валовой добавленной стоимости сельского хозяйства определяется экспертным путем за счет различных корректировок, что приводит к высокой доходности отрасли. Доходность сельского хозяйства по данным макроэкономической статистики значительно выше средней по экономике, при этом эффективность хозяйств населения в несколько раз превышает эффективность сельскохозяйственных организаций. Оценка доходности сельского хозяйства может быть определена на основе показателя макроэкономической рентабельности, величина которого будет завышаться ввиду большого удельного веса в сельском хозяйстве личных подсобных хозяйств. Выявленные недостатки подсчета доходов сельского хозяйства и его доходности требуют корректировки величины добавленной стоимости по сектору «домашние хозяйства». На основе предложенной методики корректировки подсчитана величина валовой добавленной стоимости сельского хозяйства в 2014- 2017 га. В последние годы наблюдается положительная тенденция экономического роста в сельском хозяйстве, однако скорректированные данные о доходности отрасли говорят, что доходность сельского хозяйства недостаточная, это может стать препятствием для дальнейшего развития.

Ключевые слова: система национальных счетов, валовая добавленная стоимость сельского хозяйства, доходность сельского хозяйства, макроэкономическая рентабельность, экономический рост в сельском хозяйстве, государственная аграрная политика. 
The importance of the system of national accounts as the main source of information on the state of the economics in general and separate branches and formation on the basis of these data of economic policy of the state is considered. The disadvantages of measuring income and profitability of agriculture in the system of national accounts at the level of the state and in the system of regional accounts at the level of certain regions that is connected with bad observability of sector "household farms" at their considerable specific weight on the branch "agriculture" are opened. The most part of a gross value from agriculture is defined by an expert way due to various adjustments that results in high profitability of the branch. The profitability of agriculture according to macroeconomic statistics is much higher than average in the economy, thus the efficiency of the farms of the population several times exceeds the efficiency of agricultural organizations. The assessment of profitability of agriculture can be defined on the basis of an indicator of macroeconomic profitability which size will be overestimated in view of big specific weight in agriculture of personal subsidiary farms. Revealed shortcomings of calculation of the income of agriculture and its profitability demand adjustment of the size of the value added on sector "household farms". On the basis of offered technique of adjustment the size of a gross value added of agriculture in 2014- 2017 is estimated. There has been a positive trend of economic growth in agriculture in recent years, however adjusted data on the industry profitability indicate that the profitability in agriculture is not sufficient, which may become a problem for further development.

Keywords: national accounts system, gross value added in agriculture, profitability of agriculture, macroeconomic profitability, economic growth in agriculture, national agricultural policy.

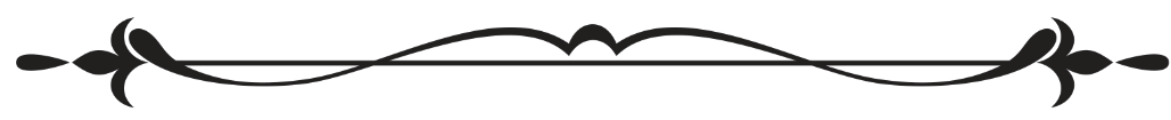

Данные системы национальных счетов широко используются органами государственного управления при разработке экономической политики. В связи с этим большое значение имеет объективная оценка доходности отдельных отраслей экономики и динамики экономического роста.

Цель исследования: разработка методики оценки доходности сельского хозяйства и экономического роста на основе данных системы национальных счетов.

В соответствии с целью исследования сформулированы следующие задачи:

1) выявить особенности подсчета доходов сельского хозяйства в системе национальных счетов;

2) разработать методику корректировки доходов сельского хозяйства в системе национальных счетов для более объективной оценки доходности и экономического роста в сельском хозяйстве; 


\section{Социально-экономический и әуманитарный журнал Красноярского ГАУ. 2019. № 4}

3) проанализировать доходность сельского хозяйства по данным системы национальных счетов;

4) проанализировать динамику экономического роста в сельском хозяйстве России.

Структура создания валового внутреннего продукта (ВВП) (доходов национальной экономики) по отраслям экономики отражается в системе национальных счетов (CHC) по добавленной стоимости. Следует отметить, что сведения об отраслевых пропорциях валовой добавленной стоимости дают только приблизительную оценку ее создания. Расхождение вызвано, прежде всего, перераспределением вновь созданной стоимости через механизм ценообразования. Анализ динамики отраслевой структуры валовой добавленной стоимости и сравнение ее с советским периодом показали сокращение доли всех отраслей, производящих товары, но в особенности сельского хозяйства. Удельный вес валовой добавленной стоимости сельского хозяйства уменьшился более чем в 4,5 раза с 16,4 \% в 1990 г. до 3,5 \% в 2018 г. Мы отмечаем, что данные о размере добавленной стоимости показывают не создание доходов, а их распределение по отдельным отраслям, исходя из сложившейся системы цен. На изменение отраслевой структуры добавленной стоимости существенно повлияло перераспределение созданной стоимости или доходов.

Кроме того, большой проблемой макроэкономической статистики сельского хозяйства является плохая наблюдаемость сектора домашних хозяйств при ее значительной доле в производстве в данной отрасли [3].

Система национальных счетов используется для подсчета результатов деятельности национальной экономики в целом по видам экономической деятельности, учитывает производственную деятельность не только организаций, но и домашних хозяйств. Валовой внутренний продукт подсчитывается как сумма добавленной стоимости по видам экономической деятельности. Валовая добавленная стоимость определяется на уровне отраслей и секторов как разность между выпуском продукции товаров и услуг и промежуточным потреблением.

Важной проблемой определения валового выпуска сельского хозяйства является оценка отдельных его компонентов. В особенности это касается фермерских хозяйств и личных подсобных хозяйств. Для оценки выпуска и промежуточного потребления сектора домашних хозяйств используются данные выборочного обследования бюджетов домашних хозяйств по проблемам занятости и другие источники, характеризующие производственную деятельность домашних хозяйств.

При определении величины валовой добавленной стоимости (ВДС) сельского хозяйства в рамках системы национальных счетов значительная ее величина приходится на экспертную оценку операций неформального сектора экономики и на производство домашних хозяйств (табл. 1). В 2005- 2010 гг. такая корректировка доходов сельского хозяй- 
ства составляла от 51,5 до 59,1 \% от валовой добавленной стоимости отрасли. В 2011-2017 гг. происходит постепенное уменьшение корректировки валовой добавленной стоимости сельского хозяйства до 38,1\%.

\section{Корректировка валовой добавленной стоимости в рамках системы национальных счетов России [7]}

Таблица 1

\begin{tabular}{|l|c|c|c|c|c|c|}
\hline \multirow{2}{*}{ Показатель } & \multicolumn{5}{|c|}{ Год } \\
\cline { 2 - 8 } & 2011 & 2012 & 2013 & 2014 & 2015 & 2017 \\
\hline $\begin{array}{l}\text { Корректировка ВДС на экономические опе- } \\
\text { рации ненаблюдаемыми прямыми стати- } \\
\text { стическими методами, \% к ВДС }\end{array}$ & 57,3 & 55,3 & 56,2 & 50,2 & 46,6 & 38,1 \\
\hline $\begin{array}{l}\text { Корректировка ВДС по виду экономической } \\
\text { деятельности «сельское хозяйство, охота и } \\
\text { лесное хозяйство» }\end{array}$ & 52,4 & 50,2 & 52,1 & 460, & 42,5 & 35,8 \\
\hline $\begin{array}{l}\text { В т. ч. на операции неформального сектора } \\
\text { экономики и на производство домашних } \\
\text { хозяйств для собственного конечного ис- } \\
\text { пользования }\end{array}$ & 16,8 & 17,1 & 16,4 & 16,0 & 16,2 & 14,0 \\
\hline
\end{tabular}

Снижение доли добавленной стоимости, получаемой в результате корректировки, связано с увеличением в последние годы доли сельскохозяйственных организаций в валовом выпуске и соответственно снижением доли домашних хозяйств. Если с 1990 до 2010 г. доля сельскохозяйственных организаций в валовом выпуске сократилась с 74 до $56 \%$ [1], то в 2014 г. удельный вес домашних хозяйств составлял уже 40 \%, а в 2017 г. - 36,5 \% (табл. 2). Однако по сравнению с другими отраслями значение данного сектора в валовом выпуске очень значительное. В 2014-1017 гг. в целом по экономике удельный вес домашних хозяйств не достигал $11 \%$.

Для выявления условий получения сельским хозяйством рыночных доходов мы определили по отдельным видам экономической деятельности и в целом по экономике на основе данных системы национальных счетов следующие показатели: удельный вес валовой добавленной стоимости в валовом выпуске, отношение добавленной стоимости к промежуточному потреблению и макроэкономическую рентабельность (табл. 3). Расчет был произведен за период 2015- 2018 гг. 


\section{Социалъно-экономический и гуманитарный журнал Красноярского ГАУ. 2019. №4}

Таблица 2

Удельный вес домашних хозяйств в валовом выпуске, \% [1, 2]

\begin{tabular}{|l|c|c|c|c|}
\hline \multicolumn{1}{|c|}{ Вид экономической деятельности } & \multicolumn{4}{|c|}{ Год } \\
\cline { 2 - 5 } & 2014 & 2015 & 2016 & 2017 \\
\hline $\begin{array}{l}\text { Сельское, лесное хозяйство, охота, рыболовство } \\
\text { и рыбоводство }\end{array}$ & 40,0 & 38,0 & 36,9 & 36,5 \\
\hline Добыча полезных ископаемых & 0,004 & 0,009 & 0,009 & 0,008 \\
\hline Обрабатывающие производства & 2,6 & 2,8 & 2,7 & 2,7 \\
\hline $\begin{array}{l}\text { Обеспечение электроэнергией, газом и паром; } \\
\text { кондиционирование воздуха }\end{array}$ & 0,029 & 0,033 & 0,031 & 0,044 \\
\hline $\begin{array}{l}\text { Водоснабжение; водоотведение, организация } \\
\text { сбора и утилизация отходов, деятельность по } \\
\text { ликвидации загрязнений }\end{array}$ & 2,1 & 2,5 & 3,0 & 2,6 \\
\hline Строительство & 7,6 & 8,9 & 9,1 & 9,0 \\
\hline Экономика в целом & 10,8 & 10,8 & 10,7 & 10,5 \\
\hline
\end{tabular}

\section{Доходность видов экономической деятельности по данным системы национальных счетов за 2015- 2018 гг.}

\begin{tabular}{|c|c|c|c|c|c|c|c|}
\hline Год & 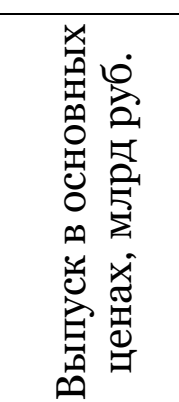 & 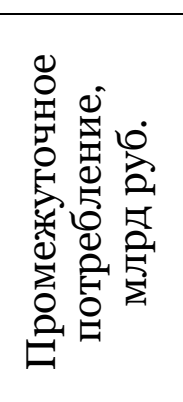 & 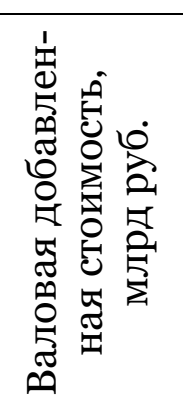 & 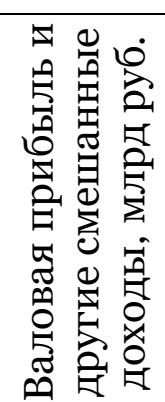 & 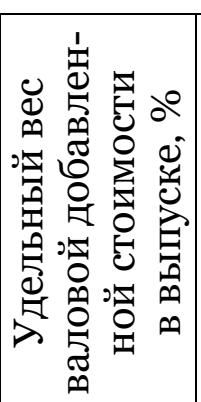 & 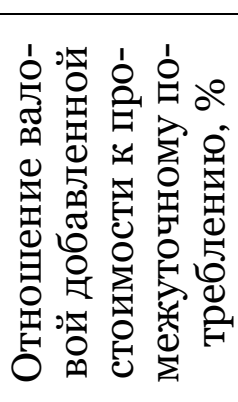 & 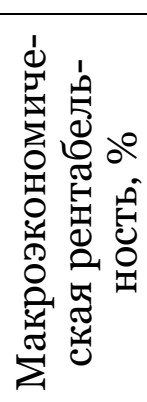 \\
\hline 1 & 2 & 3 & 4 & 5 & 6 & 7 & 8 \\
\hline \multicolumn{8}{|c|}{ Сельское, лесное хозяйство, охота, рыболовство и рыбоводство } \\
\hline 2015 & 5984,7 & 2770,0 & 3214,8 & 2575,8 & 53,7 & 116,1 & 75,6 \\
\hline 2016 & 6411,9 & 3099,7 & 3312,2 & 2603,2 & 51,7 & 106,9 & 68,3 \\
\hline 2017 & 6477,8 & 3207,5 & 3270,3 & 2461,1 & 50,5 & 102,0 & 61,3 \\
\hline 2018 & 6559,0 & 3290,4 & 3268,6 & 2415,8 & 49,8 & 99,3 & 58,3 \\
\hline \multicolumn{8}{|c|}{ Добыча полезных ископаемых } \\
\hline 2015 & 10934,1 & 3658,2 & 7275,8 & 6108,9 & 66,5 & 198,9 & 126,6 \\
\hline 2016 & 11392,2 & 3952,6 & 7439,6 & 6164,3 & 65,3 & 188,2 & 117,9 \\
\hline 2017 & 13644,0 & 4711,1 & 8932,8 & 7514,4 & 65,5 & 189,6 & 122,6 \\
\hline 2018 & 18036,6 & 6074,6 & 11962,0 & 10417,1 & 66,3 & 196,9 & 136,7 \\
\hline \multicolumn{8}{|c|}{ Обрабатывающие производства } \\
\hline 2015 & 36209,8 & 25841,6 & 10368,2 & 6332,1 & 28,6 & 40,1 & 21,2 \\
\hline 2016 & 38 156,2 & 27825,3 & 10330,9 & 6123,4 & 27,1 & 37,1 & 19,1 \\
\hline 2017 & 41420,9 & 30168,3 & 11252,6 & 6736,7 & 27,2 & 37,3 & 19,4 \\
\hline 2018 & 47677,8 & 34894,2 & 12783,6 & 7919,2 & 26,8 & 36,6 & 19,9 \\
\hline \multicolumn{8}{|c|}{ Обеспечение электроэнергией, газом и паром; кондиционирование воздуха } \\
\hline 2015 & 6954,3 & 4877,4 & 2076,9 & 1020,7 & 29,9 & 42,6 & 17,2 \\
\hline 2016 & 7566,7 & 5342,5 & 2224,2 & 1103,9 & 29,4 & 41,6 & 17,1 \\
\hline
\end{tabular}




\begin{tabular}{|c|c|c|c|c|c|c|c|}
\hline \multicolumn{8}{|c|}{ Окончание табл. 3} \\
\hline 1 & 2 & 3 & 4 & 5 & 6 & 7 & 8 \\
\hline 2017 & 7859,0 & 5464,1 & 2394,9 & 1209,3 & 30,5 & 43,8 & 18,2 \\
\hline 2018 & 8307,9 & 5775,1 & 2532,8 & 1255,9 & 30,5 & 43,9 & 17,8 \\
\hline \multicolumn{8}{|c|}{$\begin{array}{l}\text { Водоснабжение. Водоотведение, организация сбора и утилизация отходов, } \\
\text { деятельность по ликвидации загрязнений }\end{array}$} \\
\hline 2015 & 980,1 & 588,6 & 391,5 & 150,4 & 39,9 & 66,5 & 18,1 \\
\hline 2016 & 909,8 & 539,9 & 369,9 & 125,3 & 40,7 & 68,5 & 16,0 \\
\hline 2017 & 1065,2 & 636,7 & 428,5 & 158,3 & 40,2 & 67,3 & 17,5 \\
\hline 2018 & 1174,5 & 707,5 & 467,0 & 181,2 & 39,8 & 66,0 & 18,2 \\
\hline \multicolumn{8}{|c|}{ Строительство } \\
\hline 2015 & 9965,6 & 5243,3 & 4722,3 & 2871,4 & 47,4 & 90,1 & 40,5 \\
\hline 2016 & 10662,7 & 5686,0 & 4976,6 & 2958,6 & 46,7 & 87,5 & 38,4 \\
\hline 2017 & 11405,0 & 6349,0 & 5055,9 & 2981,2 & 44,3 & 79,6 & 35,4 \\
\hline 2018 & 12631,4 & 7067,9 & 5563,5 & 3290,7 & 44,0 & 78,7 & 35,2 \\
\hline \multicolumn{8}{|c|}{ Әкономика в целом } \\
\hline 2015 & 145956,2 & 71328,7 & 74627,5 & 44794,8 & 51,1 & 104,6 & 44,3 \\
\hline 2016 & 153856,5 & 76381,2 & 77475,3 & 46036,0 & 50,4 & 101,4 & 42,7 \\
\hline 2017 & 166329,3 & 83173,7 & 83155,6 & 49651,5 & 50,0 & 100,0 & 42,6 \\
\hline 2018 & 185534,3 & 92734,7 & 92799,5 & 55956,5 & 50,0 & 100,1 & 43,2 \\
\hline
\end{tabular}

Показатель макроэкономической рентабельности был рассчитан нами как аналог показателя рентабельности производства для предприятия (отношение прибыли и других смешанных доходов к затратам, промежуточное потребление, оплата труда с начислениями и амортизация).

Перечисленные показатели должны отражать доходность и условия формирования рыночных доходов отдельных видов экономической деятельности. Данные свидетельствуют о благоприятной ситуации, складывающейся для сельского хозяйства. Однако проведенный нами анализ показал, что это связано только с особенностями расчета показателей в системе национальных счетов. Относительные данные по доле добавленной стоимости сельского хозяйства по сравнению с другими отраслями очень сильно искажаются в системе национальных счетов.

Валовой выпуск в СНС по сектору «домашние хозяйства» завышается за счет высоких цен продукции, не поступающей на рынок, а величина промежуточного потребления, наоборот, занижается. Такая ситуация приводит к тому, что валовая добавленная стоимость занимает большой удельный вес в выпуске домашних хозяйств и значительную долю в валовой добавленной стоимости в целом по отрасли. Так, отношение валовой добавленной стоимости домашних хозяйств к промежуточному потреблению составляло в 2017 г. 174,8 \%, в то время как по организациям - 74,2 \% (табл. 4). Вместе с тем следует отметить следующую тенденцию: в последние годы по данным системы национальных счетов доходность домашних хозяйств падает, а организаций - растет, что может быть связано с повышением точности подсчета показателей хозяйств населения и повышением эффективности сельскохозяйственных организаций. 


\section{Социально-экономический и әуманитарный журнал Красноярского ГАУ. 2019. № 4}

\section{Формирование валовой добавленной стоимости}

в сельскохозяйственном производстве по секторам экономики

\begin{tabular}{|c|c|c|c|c|c|c|}
\hline \multirow{2}{*}{ Показатель } & \multicolumn{6}{|c|}{ Год } \\
\hline & 2005 & 2010 & 2014 & 2015 & 2016 & 2017 \\
\hline Валовой выпуск, млрд руб.: & 1611,6 & 2833,6 & 4983,8 & 5984,7 & 6411,9 & 6477,8 \\
\hline нефинансовые корпорации & 902,5 & 1561,2 & 2935,4 & 3653,8 & 3992,2 & 4077,0 \\
\hline домашние хозяйства & 692,7 & 1242,0 & 1992,4 & 2274,8 & 2365,2 & 2365,9 \\
\hline государственное управление & 16,5 & 30,3 & 56,0 & 56,1 & 54,5 & 35,0 \\
\hline $\begin{array}{l}\text { Промежуточное потребление, } \\
\text { млрд руб.: }\end{array}$ & 747,4 & 1351,4 & 2327,5 & 2770,0 & 3099,7 & 3207,5 \\
\hline нефинансовые корпорации & 549,1 & 971,6 & 1675,2 & 2056,8 & 2310,0 & 2340,5 \\
\hline домашние хозяйства & 193,7 & 373,4 & 639,7 & 700,5 & 777,1 & 861,0 \\
\hline государственное управление & 4,6 & 6,4 & 12,6 & 12,6 & 12,6 & 6,0 \\
\hline $\begin{array}{l}\text { Валовая добавленная стоимость, } \\
\text { млрд руб.: }\end{array}$ & 864,2 & 1482,2 & 2656,3 & 3214,8 & 3312,2 & 3270,3 \\
\hline нефинансовые корпорации & 353,3 & 589,6 & 1260,2 & 1596,9 & 1682,2 & 1736,4 \\
\hline домашние хозяйства & 499,0 & 868,6 & 1352,7 & 1574,3 & 1588,1 & 1504,9 \\
\hline государственное управление & 11,9 & 23,9 & 43,4 & 43,5 & 41,9 & 29,0 \\
\hline $\begin{array}{l}\text { Отношение валовой добавленной } \\
\text { стоимости к промежуточному по- } \\
\text { треблению, \%: }\end{array}$ & 115,6 & 109,7 & 114,1 & 116,1 & 106,9 & 102,0 \\
\hline нефинансовые корпорации & 64,3 & 60,7 & 75,2 & 77,6 & 72,8 & 74,2 \\
\hline домашние хозяйства & 257,6 & 232,6 & 211,4 & 224,7 & 204,4 & 174,8 \\
\hline государственное управление & 259,8 & 373,4 & 344,8 & 346,1 & 334,0 & 484,1 \\
\hline
\end{tabular}

Проведенный нами анализ позволил выявить глобальную диспропорцию в статистике сельского хозяйства, которая оказывает крайне негативное воздействие на развитие отрасли. Грубое искажение статистических данных приводит к неправильному восприятию происходящих в обществе процессов и в дальнейшем - к принятию ошибочных направлений в области государственного регулирования экономики.

Отмеченная нами глобальная диспропорция проявляется в высокой макроэкономической рентабельности сельского хозяйства по данным системы национальных счетов. На основе данных системы национальных счетов России мы провели расчет макроэкономической рентабельности сельского хозяйства в целом и в разрезе отдельных секторов (организации и хозяйства населения) за 2017 г. Полученные данные за 2017 г. и источники для их определения представлены в таблице 5. Pезультат проведенных нами расчетов показывает глобальную диспропорцию в формировании рыночных доходов сельского хозяйства России. 


\section{Таблица 5 \\ Расчет макроэкономической рентабельности сельского хозяйства в 2017 г. по данным системы национальных счетов}

\begin{tabular}{|c|c|c|c|c|}
\hline Показатель & 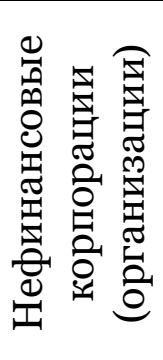 & 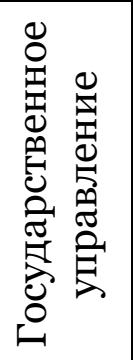 & 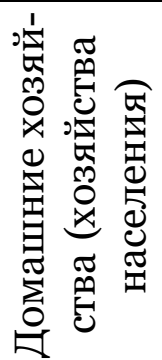 & 它 \\
\hline Валовой выпуск в основных ценах, млрд руб. & 4077,0 & 35,0 & 2365,9 & 6477,8 \\
\hline Промежуточное потребление, млрд руб. & 2340,5 & 6,0 & 861,0 & 3207,5 \\
\hline Валовая добавленная стоимость, млрд руб. & 1736,4 & 29,0 & 1504,9 & 3270,3 \\
\hline \multicolumn{5}{|l|}{ В т.Ч.: } \\
\hline оплата труда & 744,6 & 14,5 & 27,6 & 786,7 \\
\hline другие чистые налоги на производство & $-9,7$ & 2,0 & 30,3 & 22,5 \\
\hline валовая прибыль и валовые смешанные доходы & 1001,6 & 12,5 & 1447,0 & 2461,1 \\
\hline $\begin{array}{l}\text { Удельный вес валовой добавленной стоимости в } \\
\text { валовом выпуске, \% }\end{array}$ & 42,6 & 82,9 & 63,6 & 50,5 \\
\hline $\begin{array}{l}\text { Отношение валовой добавленной стоимости к } \\
\text { промежуточному потреблению, \% }\end{array}$ & 74,2 & 484,1 & 174,8 & 102,0 \\
\hline Затраты на производство продукции, млрд руб. & 3075,4 & 22,5 & 918,9 & 4016,7 \\
\hline Прибыль, млрд руб. & 1001,6 & 12,5 & 1447,0 & 2461,1 \\
\hline Макроэкономическая рентабельность, \% & 32,6 & 55,7 & 157,5 & 61,3 \\
\hline
\end{tabular}

В 2017 г. макроэкономическая рентабельность сельскохозяйственного производства в целом составила 61,3 \%, в том числе по сельскохозяйственным организациям - 32,6 \%, а по хозяйствам населения 157,5 \%! Для сравнения макроэкономическая рентабельность в целом по экономике составляла в 2017 г. 42,6 \%. Мы отмечаем наличие здесь серьезной глобальной макроэкономической диспропорции, искажающей результаты сельскохозяйственной деятельности в плане формирования доходов и, что более важно, дающей необъективную информацию для последующего процесса государственного регулирования экономики.

Отмеченные нами особенности макроэкономической статистики сельского хозяйства требуют корректировки валовой добавленной стоимости отрасли, представленной в системе национальных счетов. Корректировку можно выполнить на основе методологической предпосылки об одинаковой эффективности сектора домашних хозяйств и нефинансовых корпораций [6]. Коэффициент корректировки будет определяться отношением величины валовой добавленной стоимости, представленной в системе национальных счетов к скорректированной величине:

$$
k=\frac{B Д C}{B Д C_{C \kappa}},
$$




\section{Социально-экономический и әуманитарный журнал Красноярского ГАУ. 2019. №}

где $\mathrm{k}$ - коэффициент корректировки валовой добавленной стоимости сельского хозяйства; ВДС - валовая добавленная стоимость сельского хозяйства по данным системы национальных счетов; ВДСск - скорректированная величина валовой добавленной стоимости сельского хозяйства.

Если упрощенно представить, что валовая добавленная стоимость формируется в результате деятельности двух секторов: нефинансовые корпорации и домашние хозяйства, - то ее величина будет равна

$$
\text { ВДС }=B B \cdot Y_{H K} \cdot Э_{H K}+B B \cdot Y_{\text {सХ }} \cdot \ni_{\text {ДХ }},
$$

где ВВ - валовой выпуск отрасли сельского хозяйства по данным системы национальных счетов; $y_{н к}-$ удельный вес в валовом выпуске нефи-

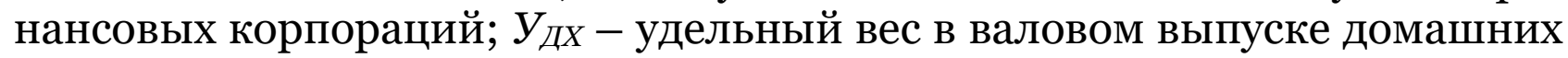
хозяйств; $Э_{н к}$ - коэффициент эффективности нефинансовых корпораций $Э_{н к}=B Д C_{H к} / B B_{H к} ; Э_{Д X}-$ коэффициент эффективности домашних хозяйств $Э_{Д X}=B Д C_{д X} / B B_{\not X}$.

Отсюда $В Д C=B B \cdot\left(Y_{H к} \cdot Э_{H к}+Y_{\text {дX }} \cdot Э_{д X}\right)$. Корректировка валовой добавленной стоимости проводится на величину завышения валовой добавленной стоимости в секторе домашних хозяйств. При этом используется методологический принцип одинаковой эффективности сектора домашних хозяйств и нефинансовых корпораций, т. е. $Э_{н к}=Э_{д X}$, а скорректированная величина валовой добавленной стоимости $В Д C_{C K}=B B \times Э_{H K}$.

Таким образом, коэффициент корректировки валовой добавленной стоимости будет равен

$$
k=\frac{B B \cdot\left(y_{H K} \cdot Э_{H K}+y_{Z X} \cdot Э_{Z X}\right)}{B B \times Э_{H K}}=\frac{y_{H K} \cdot Э_{H K}+y_{Z X} \cdot Э_{Z X}}{Э_{H K}}
$$

или

$$
k=\frac{y_{H K} \cdot Э_{H K}+y_{\text {सX }} \cdot Э_{H K} \cdot k_{\ni}}{Э_{H K}},
$$

где $\mathrm{k}_{\ni}$ - коэффициент, показывающий во сколько раз эффективность домашних хозяйств по данным системы национальных счетов выше эффективности нефинансовых корпораций, $k_{\ni}=Э_{д X} / Э_{н к}$. Данный коэффициент одновременно показывает, во сколько раз по данным системы национальных счетов завышена эффективность сектора домашних хозяйств.

В результате мы получили коэффициент корректировки валовой добавленной стоимости, который зависит от удельного веса в валовом выпуске домашних хозяйств и коэффициента их эффективности по дан- 
ным системы национальных счетов: $k=\frac{\ni_{H K} \cdot\left(Y_{H K}+V_{Z X} \cdot k_{\ni}\right)}{Э_{H K}}=y_{H K}+y_{\text {дХ }} \cdot k_{\ni}$. Поскольку $y_{Z X}+y_{H \kappa}=1$, то получаем окончательную величину коэффициента корректировки валовой добавленной стоимости сельского хозяйства:

$$
k=1+y_{\not X} \cdot\left(k_{\ni}-1\right) .
$$

Полученную формулу можно использовать для корректировки величины валовой добавленной стоимости как на уровне России в целом, так и на уровне региона. Например, если в регионе удельный вес хозяйств населения в производстве продукции сельского хозяйства составляет 55 \%, а их эффективность превышает эффективность сельскохозяйственных организаций в два раза, то коэффициент корректировки будет равен $1,55(k=1+0,55 \cdot(2-1))$.

Коэффициент эффективности сектора домашних хозяйств можно взять на основе анализа данных системы национальных счетов России. Расчет экономической эффективности сельскохозяйственного производства по секторам за 2005-2017 гг. представлен в таблице 6.

Таблица 6

\section{Экономическая эффективность производства по виду экономической деятельности «сельское хозяйство, охота и лесное хозяйство» по институциональным секторам}

\begin{tabular}{|c|c|c|c|c|c|c|}
\hline \multirow{2}{*}{ Показатель } & \multicolumn{6}{|c|}{ Год } \\
\hline & 2005 & 2010 & 2014 & 2015 & 2016 & 2017 \\
\hline 1 & 2 & 3 & 4 & 5 & 6 & 7 \\
\hline Валовой выпуск, млрд руб.: & 1611,6 & 3031,8 & 4983,8 & 5984,7 & 6411,9 & 6477,8 \\
\hline нефинансовые корпорации & 902,5 & 1690,7 & 2935,4 & 3653,8 & 3992,2 & 4077,0 \\
\hline домашние хозяйства & 692,7 & 1312,7 & 1992,4 & 2274,8 & 2365,2 & 2365,9 \\
\hline $\begin{array}{l}\text { Валовая добавленная } \\
\text { стоимость, млрд руб.: }\end{array}$ & 864,2 & 1473,2 & 2656,3 & 3214,8 & 3312,2 & 3270,3 \\
\hline нефинансовые корпорации & 353,3 & 579,8 & 1260,2 & 1596,9 & 1682,2 & 1736,4 \\
\hline домашние хозяйства & 499 & 871,0 & 1352,7 & 1574,3 & 1588,1 & 1504,9 \\
\hline $\begin{array}{l}\text { Экономическая эффектив- } \\
\text { ность (удельный вес вало- } \\
\text { вой добавленной стоимо- } \\
\text { сти в валовом выпуске), \%: }\end{array}$ & 53,6 & 48,6 & 53,3 & 53,7 & 51,7 & 50,5 \\
\hline нефинансовые корпорации & 39,1 & 34,3 & 42,9 & 43,7 & 42,1 & 42,6 \\
\hline домашние хозяйства & 72,0 & 66,4 & 67,9 & 69,2 & 67,1 & 63,6 \\
\hline $\begin{array}{l}\text { Коэффициент экономиче- } \\
\text { ской эффективности до- } \\
\text { машних хозяйств }\end{array}$ & 1,840 & 1,935 & 1,581 & 1,583 & 593 & 1,493 \\
\hline
\end{tabular}




\section{Социалъно-экономический и гуманитарный журнал Красноярского ГАУ. 2019. №4}

\begin{tabular}{|c|c|c|c|c|c|c|}
\hline \multicolumn{7}{|c|}{ Окончание табл. 6} \\
\hline 1 & 2 & 3 & 4 & 5 & 6 & 7 \\
\hline $\begin{array}{l}\text { Удельный вес домашних хо- } \\
\text { зяйств в валовом выпуске, \% }\end{array}$ & 43,0 & 43,3 & 40,0 & 38,0 & 36,9 & 36,5 \\
\hline $\begin{array}{l}\text { Коэффициент корректи- } \\
\text { ровки валовой добавлен- } \\
\text { ной стоимости }\end{array}$ & 1,361 & 1,405 & 1,232 & 1,222 & 1,219 & 1,180 \\
\hline $\begin{array}{l}\text { Скорректированная вели- } \\
\text { чина валовой добавленной } \\
\text { стоимости, млрд руб.: }\end{array}$ & 634,9 & 1048,7 & 2155,3 & 2631,3 & 2717,3 & 2770,9 \\
\hline $\begin{array}{l}\text { Завышение величины ва- } \\
\text { ловой добавленной стои- } \\
\text { мости в системе нацио- } \\
\text { нальных счетов, \%: }\end{array}$ & 36,1 & 40,5 & 23,2 & 22,2 & 21,9 & 18,0 \\
\hline
\end{tabular}

Данные таблицы 6 показывают отмеченную нами диспропорцию в эффективности хозяйств населения и сельскохозяйственных организаций. По данным макроэкономической статистики, эффективность деятельности по производству продукции сельского хозяйства в хозяйствах населения за период 2005- 2017 гг. превышала эффективность в организациях в 1,2-1,4 раза, что, по нашему мнению, не является действительностью. Так, в 2017 г. удельный вес валовой добавленной стоимости в валовом выпуске по сектору «домашние хозяйства» составлял 63,6 \%, а по сектору нефинансовых корпораций - 42,6 \%. При удельном весе домашних хозяйств в валовом выпуске 36,5 \% коэффициент корректировки, показывающий завышение валовой добавленной стоимости сельского хозяйства в макроэкономической статистике, составил 1,180. За период с 2014 по 2017 г. завышение величины доходов сельского хозяйства в макроэкономической статистике составляло, по нашим расчетам, от 18,0 до 23,2 \%.

Полученная скорректированная величина дохода сельского хозяйства может быть использована для определения динамики экономического роста в 2014-2017 гг. (табл. 7).

\section{Динамика реальной величины валовой добавленной стоимости к 2014 г.}

Таблица 7

\begin{tabular}{|l|c|c|c|c|}
\hline \multirow{2}{*}{ Показатель } & \multicolumn{4}{|c|}{ Год } \\
\cline { 2 - 5 } \multicolumn{1}{|c|}{1} & 2014 & 2015 & 2016 & 2017 \\
\hline \multicolumn{1}{|c|}{} & 2 & 3 & 4 & 5 \\
\hline Валовая добавленная стоимость, млрд руб. & 2656,3 & 3214,8 & 3312,2 & 3270,3 \\
\hline $\begin{array}{l}\text { Дефлятор валовой добавленной стоимости } \\
\text { к предыдущему гоцу, \% }\end{array}$ & & 118,2 & 100,8 & 97,3 \\
\hline $\begin{array}{l}\text { Дефлятор валовой добавленной стоимости } \\
\text { к 2014 г., \% }\end{array}$ & 100,0 & 118,2 & 119,1 & 115,9 \\
\hline $\begin{array}{l}\text { Величина валовой добавленной стоимости } \\
\text { в ценах 2014 г., млрд руб. }\end{array}$ & 2 656,3 & 2719,8 & 2780,0 & 2821,0 \\
\hline
\end{tabular}




\begin{tabular}{l|c|c|c|c|c|}
\hline \multicolumn{1}{c}{1} & \multicolumn{5}{c}{ Окончанце табл. 7} \\
\hline \multicolumn{1}{c|}{1} & 2 & 3 & 4 & 5 \\
\hline $\begin{array}{l}\text { Коэффициент корректировки валовой добав- } \\
\text { ленной стоимости }\end{array}$ & 1,232 & 1,222 & 1,219 & 1,180 \\
\hline $\begin{array}{l}\text { Скорректированная величина валовой добав- } \\
\text { ленной стоимости, млрд руб. }\end{array}$ & 2155,3 & 2631,3 & 2717,3 & 2770,9 \\
\hline $\begin{array}{l}\text { Скорректированная величина валовой добав- } \\
\text { ленной стоимости в ценах 2014 г., млрд руб. }\end{array}$ & 2 155,3 & 2226,1 & 2280,7 & 2390,2 \\
\hline $\begin{array}{l}\text { Прирост реальной величины валовой добав- } \\
\text { ленной стоимости к 2014 г., млрд руб. }\end{array}$ & - & 70,8 & 125,4 & 234,9 \\
\hline $\begin{array}{l}\text { Темп реального роста валовой добавленной } \\
\text { стоимости к 2014 г., \% }\end{array}$ & - & 3,3 & 5,8 & 10,9 \\
\hline
\end{tabular}

Используя дефлятор валовой добавленной стоимости, можно получить ее величину в сопоставимых ценах 2014 г. (реальный доход). Его динамика показана на рисунке.

В последние годы наблюдается тенденция экономического роста в сельском хозяйстве, что связано с осуществлением Государственной программы развития АПК. В 2017 г. реальные доходы сельского хозяйства России выросли относительно уровня 2014 г. на 234,9 млрд руб., или на $10,9 \%$. Несмотря на положительные тенденции в сельском хозяйстве, необходимо отметить, что главная проблема сельского хозяйства России, обуславливающая многие существующие негативные тенденции, связана с его низкой доходностью, вследствие чего многие сельскохозяйственные товаропроизводители не способны использовать научнотехнические достижения для повышения эффективности и конкурентоспособности производимой ими продукции.

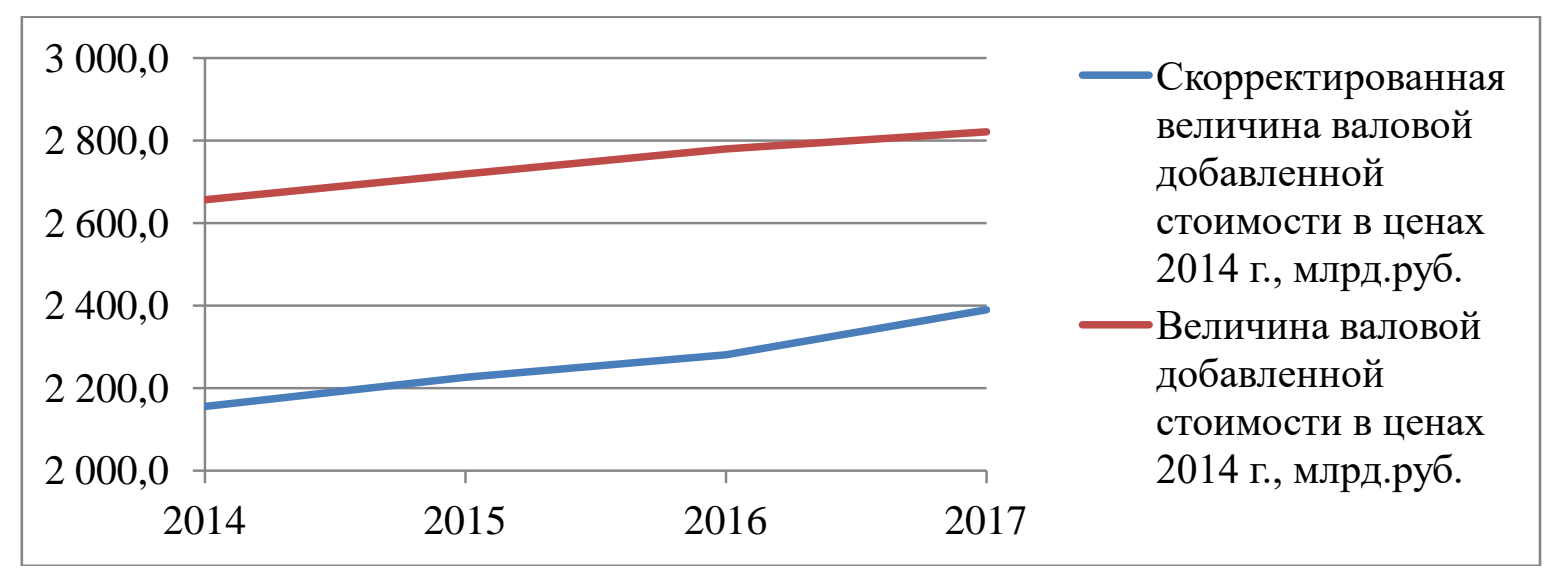

Динамика экономического роста в сельском хозяйстве России в 2014-2017 г2.

Выводы. В настоящее время в силу объективных причин система национальных счетов не дает правильного представления о доходности сельского хозяйства. Для более объективной оценки доходности сельского хозяйства и динамики экономического роста необходима корректировка его доходов, которая возможна по предлагаемой нами методике. Для оценки 


\section{Социально-экономический и әуманитарный журнал Красноярского ГАУ. 2019. № 4}

доходности сельского хозяйства в системе национальных счетов целесообразно использовать показатель макроэкономической рентабельности.

Проведенный нами анализ говорит о положительной динамике экономического роста в сельском хозяйстве в последние годы. Вместе с этим следует отметить недостаточную доходность сельского хозяйства, о чем говорит показатель макроэкономической рентабельности, рассчитанный на основе скорректированной величины валовой добавленной стоимости.

\section{Литература}

1. Национальные счета России в 2004-2011 годах: стат. сб. / Росстат. M., 2012.

2. Национальные счета России в 2014-2018 годах: стат. сб. / Росстат. М., 2019.

3. Зинченко А.П. Сельское хозяйство России и СНС // Экономика сельскохозяйственных и перерабатывающих предприятий. - 2005. - № 5 .

4. Плышиевский Б.П. Где создается и как расходуется национальный продукт России. - М.: Статистика России, 2006.

5. Растянников В.Г., Дерюгина И.В. Экономический рост в аграрном секторе России. Проблемы XX века / Рос. акад. наук, Ин-т востоковедения. М.: Статистика России, 2005.

6. Комшанов Д.С., Мальишева А.Б., Можарова И.В. Формирование рыночных доходов и экономический рост в сельском хозяйстве (вопросы теории и методологии). - Великие Луки: Изд-во ВГСХА, 2012.

7. Федеральная служба государственной статистики. - URL: http://gks.ru.

\section{Literatura}

1. Nacional'nye scheta Rossii v 2004-2011 godah: stat. sb. / Rosstat. M., 2012.

2. Nacional'nye scheta Rossii v 2014-2018 godah: stat. sb. / Rosstat. M., 2019.

3. Zinchenko A.P. Sel'skoe hozjajstvo Rossii i SNS // Jekonomika sel'skohozjajstvennyh i pererabatyvajushhih predprijatij. - 2005. - № 5 .

4. Plyshevskij B.P. Gde sozdaetsja i kak rashoduetsja nacional'nyj produkt Rossii. - M.: Statistika Rossii, 2006.

5. Rastjannikov V.G., Derjugina I.V. J ekonomicheskij rost v agrarnom sektore Rossii. Problemy XX veka / Ros. akad. nauk, In-t vostokovedenija. - M.: Statistika Rossii, 2005.

6. Komshanov D.S., Malysheva A.B., Mozharova I.V. Formirovanie rynochnyh dohodov i jekonomicheskij rost v sel'skom hozjajstve (voprosy teorii i metodologii). - Velikie Luki: Izd-vo VGSHA, 2012.

7. Federal'naja sluzhba gosudarstvennoj statistiki. - URL: http:// gks.ru.

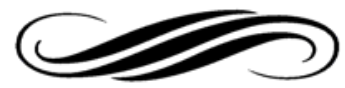

